\title{
Altered antioxidant enzyme activity with severity and comorbidities of chronic obstructive pulmonary disease (COPD) in South Indian population
}

Asimuddin Mohammed ${ }^{1,2^{*}}$, Vijayalakshmi Gutta ${ }^{1}$, Mohd Soheb Ansari ${ }^{4}$, Rajagopal Saladi Venkata ${ }^{3}$ and Kaiser Jami ${ }^{2,4}$

\begin{abstract}
Background: Oxidative stress has been suggested in the pathogenesis of Chronic Obstructive Pulmonary Disease (COPD) with an additional burden of diabetes, hypertension and cardiovascular disease. In the present study, we investigated erythrocyte antioxidant enzymes activities in correlation to COPD severity and COPD comorbidities.

Methods: One hundred twenty seven subjects with COPD and 59 healthy controls participated in this study. COPD severity was done based on the Global Initiative for Chronic Obstructive Lung Disease criteria. The erythrocytes enzyme activities of superoxide dismutase (SOD), catalase (CAT), glutathione-s-transferase (GST), glutathione peroxidase (GPx), glutathione reductase (GR) and total antioxidant status (TAS) were measured with spectrophotometric method.

Results: COPD patients showed significant decrease in TAS $(p>0.05)$, GST $(p<0.001)$ and GPx $(p<0.01)$ activities with progression of the disease. In patients, FEV , was negatively correlated with SOD, GR and positively correlated with GST and GPx activities. Further, multivariate logistic regression analysis revealed GST (OR $=0.93 ; 95 \% \mathrm{Cl}=-0.10-0.01 ; p<0.01$ ) , $\mathrm{GPx}(\mathrm{OR}=0.98 ; 95 \% \mathrm{Cl}=-0.03-0.00 ; p<0.05)$ and TAS $(\mathrm{OR}=0.95 ; 95 \% \mathrm{Cl}=-0.08-0.00 ; p<0.05)$ were independently associated with $\mathrm{FEV}_{1}$ in GOLD stage IV and GST (OR $\left.=1.11 ; 95 \% \mathrm{Cl}=0.04-0.18 ; p<0.001\right)$ in GOLD stage II. Regression analysis confirmed a significant difference in GPx activity in COPD - type 2 diabetes $(\mathrm{OR}=0.04 ; 95 \% \mathrm{Cl}=-6.60-0.53$; $P=0.09)$, and GST activity in COPD - cardiovascular disease $(\mathrm{OR}=2.51 ; 95 \% \mathrm{Cl}=0.00-1.84 ; p<0.05)$ patients when compared to patients without comorbidities.

Conclusion: A significant decline in lung function may be associated with altered antioxidant enzyme activity due to the strong correlation between GST and GPx with COPD severity. Our results also indicate that erythrocytes GST and GPX activities are significantly associated with comorbidities, but only in COPD patients with type 2 diabetes and cardiovascular disease.
\end{abstract}

Keywords: Erythrocyte, Antioxidant enzyme, COPD, GOLD stage classification, Lung function test, Forced expiratory volume in $1 \mathrm{~s}$, Diabetes, Hypertension, Cardiovascular disease

\footnotetext{
*Correspondence: mmast7@gmail.com

'Department of Biotechnology, GITAM Institute of Science, GITAM University,

Visakhapatnam, Andhra Pradesh 530045, India

${ }^{2}$ Center for Biotechnology and Bioinformatics (CBB), Jawaharlal Nehru

Institute of Advance Studies (JNIAS), Hyderabad 500003, Telangana, India

Full list of author information is available at the end of the article
} 


\section{Background}

Chronic obstructive pulmonary disease (COPD) is a disease characterized by irreversible and progressive airflow obstruction that is associated with lung inflammation, according to American Thoracic Society guidelines [1]. The most common causes of COPD are cigarette smoking, environmental exposure to dust particles and air pollutants such as allergens, bacterial and viral spores [2]. The lungs are the organs that are continuously exposed to oxidants, either generated from inside the body or from outside the body due to exposure to air pollution or cigarette smoke. These particles increase the levels of oxidants in the lungs, and have the potential to interact with biological systems to produce oxidative stress, which results in the destruction of alveoli, the tiny air sacs in the lungs where the exchange of oxygen and carbon dioxide takes place, and also results in narrowing of airway lumen diameters. Oxidative stress promotes inflammation of the airways of the lungs as seen in COPD patients.

This causes an irreversible decrease in reduction of forced expiratory volume in $1 \mathrm{~s}\left(\mathrm{FEV}_{1}\right)$ as seen in COPD cases [3]. COPD is a major, ever increasing global health problem due to increase in smoking rates and lifestyle changes and is projected to be the fourth leading cause of death worldwide by 2030 [4]. A report submitted by National Commission on Macroeconomics and Health $(\mathrm{NCMH})$, showed that the incidence of COPD in India may increase from 17.0 million (in the year 2006) to 22.2 million by 2016 [5].

Oxidative stress, being the major risk factor in the pathogenesis of COPD, is caused by the generation of free oxygen radicals (ROS) [6]. Excessive cigarette smoking or environmental exposure to smoke and airpollutants has been shown to settle in the lungs, leading to increased production of ROS causing oxidative stress [7]. Another prominent source of ROS is either environmental derived or cell-derived, both of these are directly associated with many chronic respiratory lung diseases, including COPD $[8,9]$. These ROS categories include superoxide anion $\left(\mathrm{O}_{2}^{-}\right)$, hydroxyl radical $(. \mathrm{OH})$, hydrogen peroxide $\left(\mathrm{H}_{2} \mathrm{O}_{2}\right)$ and nitric oxide (NO.) radicals [10]. In order to maintain the balance of oxidative stress caused by ROS, the body has to balance between enzymatic and non-enzymatic antioxidants $[11,12]$. The main function of antioxidant enzymes is to neutralize the free radicals and transform them into safer $\left(\mathrm{O}_{2}^{-}\right)$. Antioxidants enzymes, such as superoxide dismutase (SOD) which detoxifies the superoxide anion and converts into $\mathrm{H}_{2} \mathrm{O}_{2}$ and $\mathrm{O}_{2}$, a less toxic product. Catalase (CAT) enzyme completes the detoxification process initiated by SOD via decomposition of $\mathrm{H}_{2} \mathrm{O}_{2}$ to water and oxygen [13]. Glutathione peroxidase (GPx) is a family of seleniumdependent and independent antioxidant enzymes [14]. There are six known isoforms of GPx and the most abundant isoforms, GPx-1, is ubiquitously expressed in the cytoplasm of all mammalian cells $[15,16]$. The main function of GPx is to detoxify hydrogen peroxide to $\mathrm{H}_{2} \mathrm{O}$ and $\mathrm{O}_{2}$. However, it also detoxifies the lipid peroxides to release water and alcohol [13]. Glutathione-s-transferase (GST) is major cytosolic phase II detoxification enzymes which inactivates reactive electrophiles by Glutathione (GSH) dependent mechanism [7, 8]. Glutathione reductase (GR) recycles the oxidized glutathione disulfide (GSSG) using NADPH as the reducing co-factor and thereby maintains an appropriate intracellular GSH level in the cell [17].

There is evidence that erythrocyte GPx activity is lower in smokers compared to non-smokers [18]. Few studies report a direct relationship between forced expiratory volume in $1 \mathrm{~s}\left(\mathrm{FEV}_{1}\right)$ and pathogenesis of COPD $[19,20]$. On the other hand, another study failed to find significant relationship between $\mathrm{FEV}_{1}$ and plasma antioxidant capacity [21]. It has been reported that erythrocytes are more exposed to oxidative stress and studies have shown that these cells are highly susceptible to oxidative damage in the development and progression of various diseases. In view of such conflicting reports, we have taken up this study to investigate the role of antioxidants in diseased patients. It is also known that comorbidities in COPD are known to cause difficulties in diagnosis and cause economic burden to patients. Metabolic complications, namely diabetes and metabolic syndrome are the most common comorbidities in COPD. Besides, some reports have demonstrated that COPD patients have a relatively increased risk of developing lung cancer, pulmonary hypertension and cardiovascular disease [22]. There are evidences that cardiovascular disease and COPD patients share the same risk factors i.e. smoking and alcohol [23]. It is not surprising to note that pulmonary hypertension which results in type 2 diabetes could also lead to COPD with significant lower $\mathrm{FEV}_{1}$ values than in non-diabetics [24]. However, it is not understood why COPD patients are at greater risk of type 2 diabetes as compared to non-diabetes subjects or vice-versa [25].

It has been a common practice to identify the antioxidant enzyme levels in plasma or serum. Furthermore, in the progression of COPD erythrocytes are highly susceptible to oxidative damage. Therefore, the present study aimed to investigate the erythrocyte antioxidant enzyme activities in COPD patients and correlate these levels with lung function test assessed as $\mathrm{FEV}_{1}$. It is also possible that the comorbidities may further increase the risk of COPD severity. We are not aware of any previous studies that addressed the erythrocyte antioxidant enzyme activities in COPD patients with comorbid diseases such as type 2 diabetes, pulmonary hypertension and cardiovascular disease. Hence, the present study also aims to investigate the relationship between the antioxidant enzymes activities of COPD patients with comorbidities. 


\section{Methods}

\section{Demographic details of patients}

One hundred twenty seven COPD patients and 59 healthy controls were participated in this study. The data regarding gender, age, body mass index (BMI) and smoking status were analyzed. All study subjects underwent a standardized clinical examination at the Outpatients clinic at Mahavir Hospital and Research Centre, Hyderabad, India. The COPD patients and controls were informed about the study and purpose; and gave written informed consent before inclusion in the study group. The study was conducted in accordance with the guidelines of Committee responsible for human studies as guided by the "Declaration of Helsinki" and good clinical practice. The Ethics Committee of Mahavir Hospital and Research Centre - Hyderabad approved the study.

Inclusion criteria: All patients recruited had confirmed COPD as determined by the Pulmonologist. The potential cases having symptoms such as chronic cough, breathing problem and production of mucus or sputum

Table 1 Association of significant demographic characteristics among study variables

\begin{tabular}{|c|c|c|}
\hline \multirow[t]{2}{*}{ Variables } & Controls & COPD \\
\hline & $\begin{array}{l}\text { Mean } \pm \text { SEM } \\
(n=59)\end{array}$ & $\begin{array}{l}\text { Mean } \pm \text { SEM } \\
(n=127)\end{array}$ \\
\hline Age, years & $51.02 \pm 0.27$ & $60.10 \pm 0.31^{* *}$ \\
\hline Male $(n)$ & $38(64.40)$ & $98(77.16)$ \\
\hline Female $(n)$ & $21(35.59)$ & $29(22.83)$ \\
\hline Weight (kg) & $65.32 \pm 1.50$ & $61.69 \pm 0.32^{* *}$ \\
\hline Height (cms) & $157.12 \pm 1.04$ & $158.50 \pm 0.26$ \\
\hline BMI $\left(\mathrm{kg} / \mathrm{m}^{2}\right)$ & $26.43 \pm 0.65$ & $24.43 \pm 0.20^{* *}$ \\
\hline \multicolumn{3}{|l|}{ Smoking Status } \\
\hline Ex-smoker $(n)$ & $13(22.03)$ & $50(39.37)$ \\
\hline current smoker $(n)$ & $17(28.81)$ & $32(25.19)$ \\
\hline non-smoker $(n)$ & $29(49.15)$ & $45(35.43$ \\
\hline \multicolumn{3}{|l|}{ Spirometry parameter } \\
\hline $\mathrm{FEV}_{1}, \%$ of predicted & $71.20 \pm 1.26$ & $36.21 \pm 0.40^{* * *}$ \\
\hline FVC, $\%$ of predicted & $83.99 \pm 1.06$ & $50.15 \pm 0.34^{* * *}$ \\
\hline $\mathrm{FEV}_{1} / \mathrm{FVC}, \%$ of predicted & $97.56 \pm 0.71$ & $70.41 \pm 0.46^{* * *}$ \\
\hline $\mathrm{PaO} 2(\mathrm{mmHg})$ & & $57.51 \pm 0.11$ \\
\hline $\mathrm{SaO} 2(\%)$ & & $90.62 \pm 0.19$ \\
\hline \multicolumn{3}{|l|}{ COPD co-morbidities } \\
\hline Type 2 diabetes $(n)$ & & $41(32.28)$ \\
\hline Pulmonary hypertension ( $n$ ) & & $52(40.94)$ \\
\hline Cardiovascular disease (n) & & $27(21.25)$ \\
\hline
\end{tabular}

Variables are expressed as Mean \pm SEM or number (\%), standard error of the mean; Significance of difference to control: ${ }^{*} p<0.05$, ${ }^{* *} p<0.001,{ }^{* * *} p<0.001$. COPD Chronic Obstructive Pulmonary Disease, BMI Body Mass Index, FEV forced $^{2}$ expiratory volume in $1 \mathrm{~s}, F V C$ force vital capacity, $F E V_{1} / F V C$ forced expiratory volume in $1 \mathrm{~s} /$ forced vital capacity ratio, $\mathrm{PaO} 2$ Partial pressure of oxygen, $\mathrm{SaO} 2$ Arterial oxygen saturation, $n$ number were reviewed by respiratory physiologist. Each patient was checked 10-15 min after administration of $200 \mu \mathrm{g}$ of salbutamol. Only patients who showed airway obstruction reversibility $<12 \%$ of forced expiratory volume in $1 \mathrm{~s}\left(\mathrm{FEV}_{1}\right)$ and or forced vital capacity $\mathrm{FVC}$, were retained for the study. The predicted values for FEV1, FVC and FEV1/FVC were generated for COPD severity. The Pulmonary function test was performed using Mir Spiro Lab II Spirometer (MIR s.r.l, Roma, Italy). At least 3 acceptable and two reproducible curves (the two highest FVC and FEV1 being within $200 \mathrm{ml}$ of each other) were obtained. Patients which showed highest values of FEV1 were selected for analysis. Spirometry measurements in COPD patients were performed as per Global Initiative for Chronic Obstructive Lung Disease (GOLD) guidelines [26]. The GOLD stage classification of disease severity was done as per Global Initiative for Chronic Obstructive Lung Disease (GOLD) guidelines [26]. GOLD stage I (mild): $\geq 80 \%$; GOLD stage II (moderate): 50-70\%; GOLD stage III (severe): $30-49 \%$ and GOLD stage IV (very severe) $<30 \%$ predicted.

Among the selected COPD study group, we found three types of comorbid diseases including type 2 diabetes, some cases with pulmonary hypertension and some cases with cardiovascular disease. These were noted for further analysis. Among the COPD patients comorbid disease analyses were limited to subjects in whom complete data on demographic factors, risk factors and baseline comorbid disease were available. The 59 volunteers selected as controls were recruited from the general population (Among these three were exsmokers, 17 current smokers and 39 non-smokers) with

Table 2 Association of significant clinical characteristics of the COPD patients according to GOLD Stage classification using Spirometry parameters

GOLD stage classification of COPD patients

Spirometry parameter GOLD stage II GOLD stage III GOLD stage IV Mean \pm SEM Mean \pm SEM Mean \pm SEM $(n=28) \quad(n=42) \quad(n=57)$

\begin{tabular}{llll}
\hline FEV,$\%$ predicted & $60.08 \pm 0.38^{* *}$ & $38.85 \pm 0.31^{* *}$ & $20.76 \pm 0.25^{* *}$
\end{tabular}

FVC, \% predicted $\quad 85.91 \pm 0.47^{* *} \quad 58.32 \pm 0.38^{* *} \quad 42.18 \pm 0.37^{* *}$

$\mathrm{FEV}_{1} / \mathrm{FVC}$, \% predicted $70.21 \pm 0.46 \quad 67.18 \pm 0.05^{* *} \quad 50.55 \pm 0.04^{* *}$

$\mathrm{PaO} 2(\mathrm{mmHg}) \quad 57.08 \pm 0.27 \quad 57.60 \pm 0.20 \quad 57.60 \pm 0.16$

$\mathrm{SaO} 2(\%) \quad 87.33 \pm 0.33^{* *} \quad 89.92 \pm 0.34^{* *} \quad 92.23 \pm 0.29^{* *}$

Variables are expressed as Mean \pm SEM, standard error of the mean; All $p$ values were calculated using ANOVA with Bonferroni post hoc test. Non-significant $p$ values, $p>0.05,{ }^{* *} p<0.01$. FEV1: GOLD stage II vs. III vs. IV, ${ }^{* *} p<0.01$; FVC: GOLD stage II vs. III vs. IV ** $p<0.01$; FEV1/FVC: GOLD stage II vs III, $p>0.05 ;$ GOLD stage II vs. III vs. IV, ${ }^{* *} p<0.01 ; \mathrm{PaO} 2$ (mmHg): GOLD stage II vs. III vs. IV, $p>0.05 ; \mathrm{SaO} 2$ (\%): GOLD stage II vs III vs. IV $p>0.05$; GOLD stage II vs IV, ${ }^{* *} p<0.01$ COPD Chronic Obstructive Pulmonary Disease, GOLD Global initiative for chronic Obstructive Lung Disease; GOLD stage classification: GOLD II- Moderate COPD, GOLD III - Severe COPD, GOLD IV - Very severe COPD; FEV 1 forced expiratory volume in $1 \mathrm{~s}, F V C$ force vital capacity, FEV $/$ /FVC forced expiratory volume in $1 \mathrm{~s} /$ forced vital capacity ratio; $\mathrm{PaO} 2$ Partial pressure of oxygen, $\mathrm{SaO} 2$ Arterial oxygen saturation 
no respiratory problems. Inclusion criteria: Exclusion criteria: All those subjects with very severe conditions, pregnant women and children with severe cough were excluded from the study.

\section{Blood sample collection and processing}

Blood samples from COPD patients and controls $(5 \mathrm{ml} /$ individual) was collected in anticoagulant vacutainers and processed immediately for analysis. Blood samples were first centrifuged at $3000 \mathrm{rpm}$ (5430R, Eppendorf, Germany) for $10 \mathrm{~min}$ and the plasma was removed. Then packed erythrocytes cells were washed three times with $0.9 \% \mathrm{NaCl}$ hypotonic solution and washed erythrocytes were lyses using ice-cold distilled water and stored at $-20{ }^{\circ} \mathrm{C}$ to determine the antioxidant enzyme estimation. The erythrocyte hemolysate was prepared as mentioned above using venous blood samples from the study group.

\section{Estimation of antioxidant enzymes in erythrocytes}

Erythrocyte hemolysates were used for the estimation of SOD, CAT, GPx, GST, GR and TAS. SOD (EC 1.15.1.1) activity was measured based on inhibition of pyrogallol oxidation by the method of Marklund and Marklund [27]. CAT (EC 1.11.1.16) activity was determined by the method of Aebi [28]. Glutathione-s-transferase [GST] (EC2.5.1.18) activity was assayed according to the method described by Beutler [29] via measurement of the conjugation product of GSH with 1-chloro-2, 4dinitrobenzene (CDNB). Glutathione peroxidase (EC 1.11.1.7) activity was measured according to the method described by Flohe and Gunzler [30]. Glutathione reductase (EC 1.6.4.2) activity was measured by the method of Carlberg and Mannervik [31]. The total antioxidant power, expressed as the Ferric Reducing Ability of the Plasma (FRAP) in erythrocytes, was analyzed by the method described by Benzie and Strain [32]. The TAS was determined using a different concentration of Ferric (II) sulfate as standard. The results were expressed in $\mu \mathrm{M} \mathrm{Fe}^{2+} / \mathrm{L}$ equivalent.

\section{Statistical analyses}

All the demographic data and spirometric parameters are presented as mean values \pm Standard Error of the Mean (SEM) using non-parametric statistics. Normality distribution was analyzed using Shapiro-Wilk test and the two-tailed $t$-test was used to analyze the statistical significance for analyses between controls and COPD patients. Comparisons between erythrocyte antioxidant enzyme activities on disease severity GOLD stages I, II, III and IV and COPD comorbidities were tested by ANOVA; post hoc test for multiple comparisons using Bonferroni correction were performed using GraphPad Prism 6 (GraphPad Software Inc, San Diego, CA, USA). GOLD stage I was excluded from the study. The

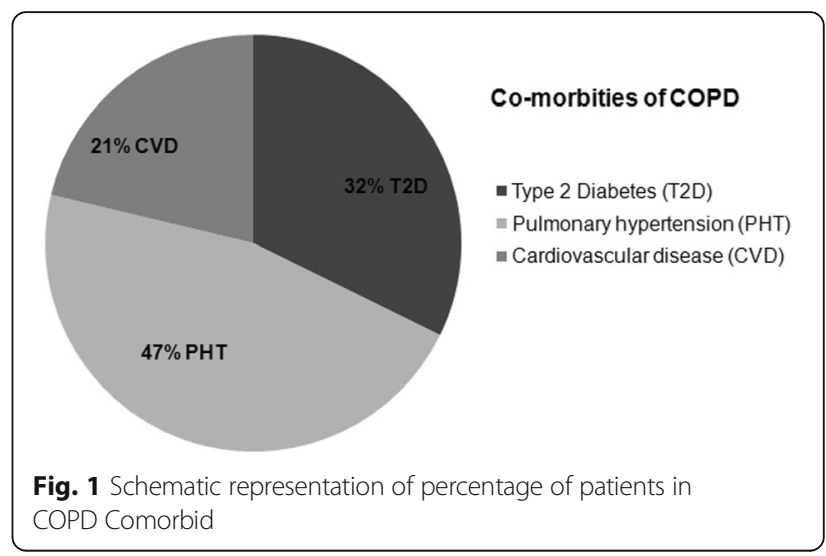

relationship between antioxidant enzyme activities and $\mathrm{FEV}_{1}$ among COPD patients were evaluated using Pearson's coefficients of correlation. Furthermore, a multivariate logistic regression model was constructed to determine Odds ratios (OR), 95\% confidence intervals (95\% CI) and significant of severity of COPD and COPD comorbidities have been calculated in order to correlate the erythrocyte antioxidant enzyme activities were analyze using the XLSTAT statistical analysis (Addinsoft, New York, NY, USA). A $p$-value of less than $0.05(p<0.05)$ was considered as statistically significant.

\section{Results}

Normality analysis showed that all the variables were normally distributed. The demographic characteristics of COPD patients and healthy controls are presented in Table 1. We found that the mean age of COPD patients was $>60$ years, whereas the mean age of control group was $>50$ years old. The mean BMI was significantly lower than that of controls $(p<0.05)$. The smoking status in COPD patients in this study was as follows: there were $39.37 \%$ ex-smokers, $25.19 \%$ current smokers and $35.43 \%$ non-smokers, whereas in controls we had $22.03 \%$ exsmokers, $28.18 \%$ current smokers and $49.15 \%$ nonsmokers respectively, Table 1 . Spirometry measurements in COPD patients as per GOLD stage classification of

Table 3 Significant association of antioxidant enzyme activities in cases and controls

\begin{tabular}{lll}
\hline Study parameters & $\begin{array}{l}\text { Healthy control } \\
n=59\end{array}$ & $\begin{array}{l}\text { COPD } \\
n=127\end{array}$ \\
\hline Superoxide dismutase (U/mg protein) & $87.56 \pm 0.48$ & $77.34 \pm 0.48^{* * *}$ \\
Catalase (U/mg protein) & $98.34 \pm 0.94$ & $72.77 \pm 0.60^{* * *}$ \\
Glutathione s transferase & $42.05 \pm 0.56$ & $21.30 \pm 0.33^{* * *}$ \\
(U/mg protein) & & \\
Glutathione peroxidase (U/mg protein) & $63.77 \pm 0.44$ & $59.43 \pm 0.50^{* * *}$ \\
Glutathione reductase (U/mg protein) & $77.08 \pm 0.96$ & $61.97 \pm 0.60^{* * *}$ \\
Total antioxidant status ( $\mu \mathrm{M}$ Fe $\left.{ }^{2+} / \mathrm{I}\right)$ & $46.19 \pm 0.27$ & $41.64 \pm 0.30^{* * *}$ \\
\hline
\end{tabular}

Variables are expressed as mean \pm SEM. Significance of difference between COPD patients compared to controls: ${ }^{* * *} P<0.001$ 
disease severity are presented in Table 2 . There were no patients belonging to GOLD stage I, GOLD stage II had 22.04\%, GOLD stage III had 33.07 and $44.88 \%$ were in GOLD stage IV. The pulmonary function test, assessed as $\mathrm{FEV}_{1}, \mathrm{FVC}$ and the ratio of $\mathrm{FEV}_{1} / \mathrm{FVC}$, showed significantly decrease in the mean value from GOLD stage II to IV in COPD patients $(p<0.001$; ANOVA followed by Bonferroni post hoc test) Table 2. No significant difference in $\mathrm{PaO} 2$ between GOLD stages II to IV $(p>0.05)$ was observed Table 2. A similar examination of $\mathrm{SaO} 2$ revealed a significant increase in levels from GOLD stage II to IV $(p<0.05)$. Comorbidities of COPD patients are summarized in Fig. 1. Of the 127 patients diagnosed with COPD, we found that $41(52.07 \%)$ were Type II diabetic, $52(74.93 \%)$ had pulmonary hypertension and 27 (34.29\%) had cardiovascular disease.

A significant decrease in the first and second-step antioxidant enzymes SOD and CAT activities was found in COPD patients $(p<0.001)$. Similar significant decrease was also observed in the erythrocyte GST, GPx, GR and TAS in COPD patients compared to controls $(p<0.001)$, results are presented in Table 3 . On
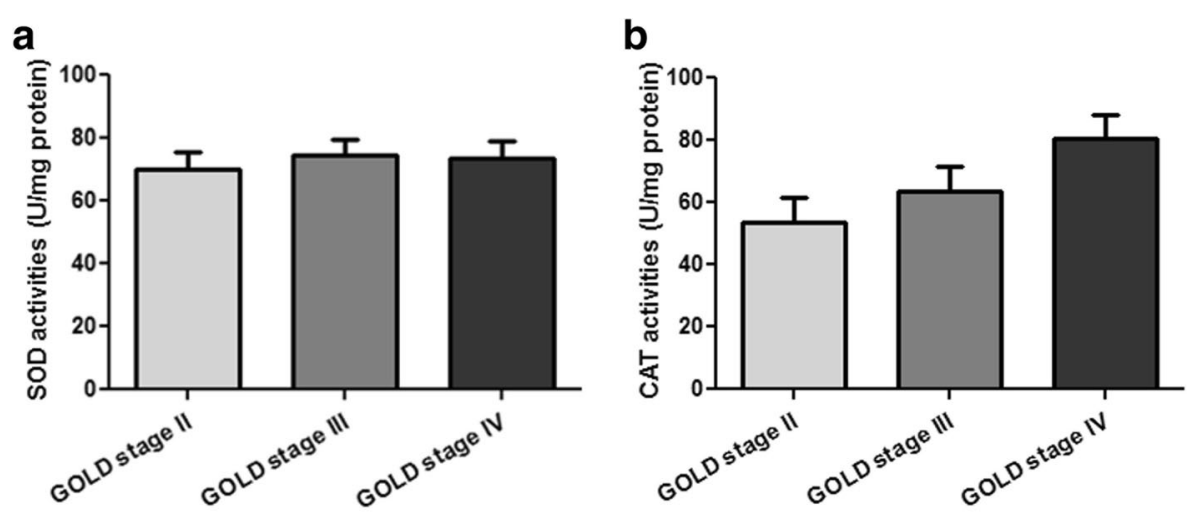

C

d
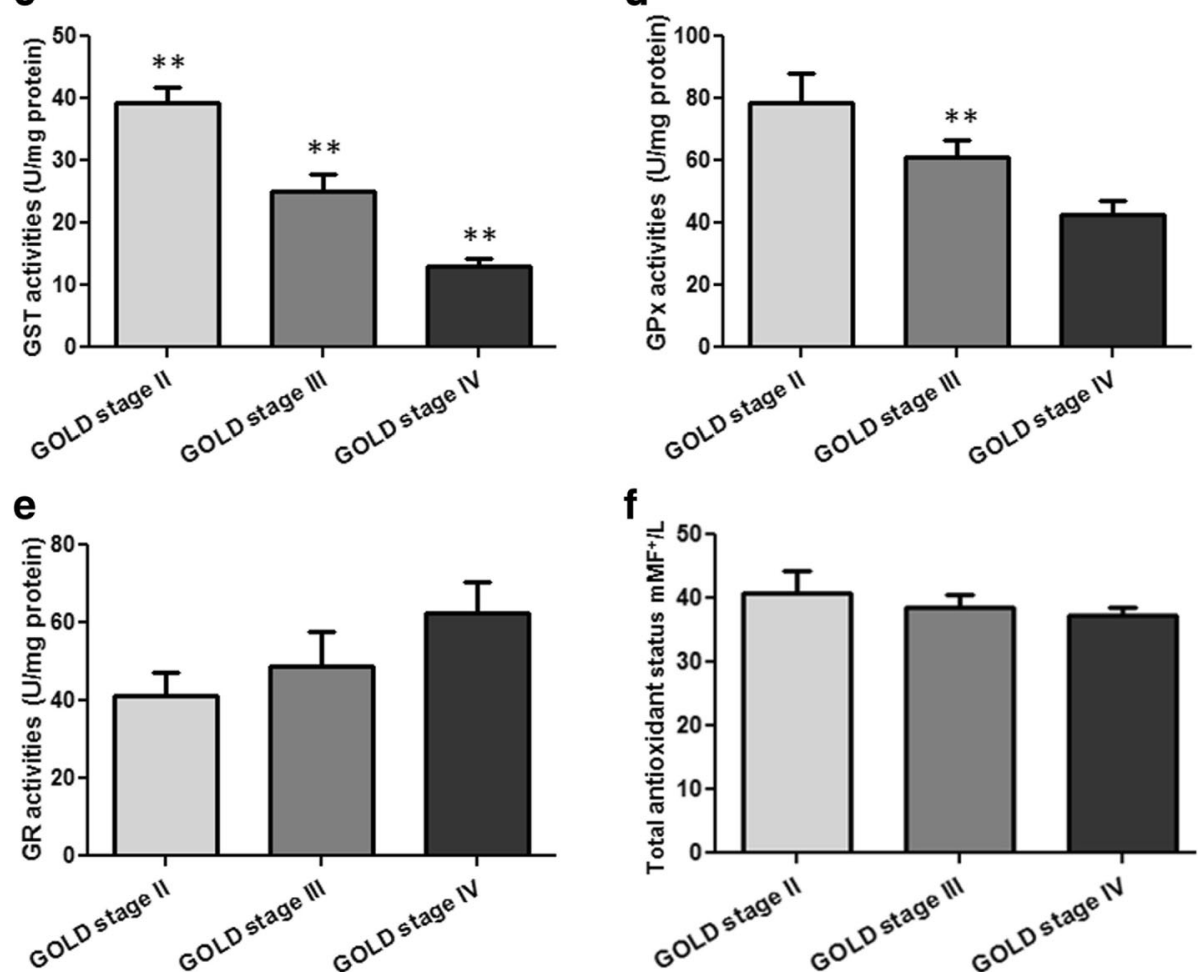

Fig. 2 Comparison of antioxidant enzyme activities according to severity of COPD using GOLD stage classification (GOLD stage II, III and IV): Erythrocytes (a) SOD, superoxide dismutase; b CAT, catalase; c GST, glutathione-s-transferase; d GPx, glutathione peroxidase; e GR, glutathione reductase; expressed as $\mathrm{U} / \mathrm{mg}$ protein and (f) TAS, total antioxidant status; expressed as $\mu \mathrm{M} \mathrm{Fe}{ }^{2+} / \mathrm{I}$. Data expressed as Mean \pm SEM: standard error of the mean; Significant of differences and respective $p$ values ${ }^{* *} p<0.001$ are mentioned on the graph using One-way ANOVA followed by Bonferroni's multiple comparison post hoc test 
comparison of erythrocyte antioxidant enzyme activities with severity of COPD, we found an increase in the mean value of SOD and CAT in stages II to IV however, this increase was not statistically significant $(p>0.05$; Fig. $2 \mathrm{a}$ and b). Conversely, a significant decrease in the mean value of GST $(p<0.001)$ and GPx $(p<0.01)$ was observed in disease stages II, III and IV respectively, (Fig. 2c and d). In contrast, the mean value of GR activity increased from stage II to IV $(p>0.05$; Fig. 2e). A decrease in the mean value of TAS was observed in stages II, III and IV ( $p>0.05$; Fig. 2f).

Variations in Pearson's coefficients of correlation values between erythrocyte anti-oxidation enzyme activities with $\mathrm{FEV}_{1}$ (\% predicted) in COPD patients are presented in Table 4. We observed negative correlation between erythrocyte SOD, CAT and TAS with $\mathrm{FEV}_{1}$ in COPD patients $(r=-0.182, \quad r=-0.263$ and $r=-0.183 ; p<0.05)$ whereas GR was not statistically significant $(r=-0.094$; $p>0.05)$. GST and GPx only entered as a model of antioxidant enzymes, showed a significant positive correlation with $\mathrm{FEV}_{1}$ in COPD patients $(r=0.630$ and $r=0.030$, respectively) (Table 4). Further, correlation analysis was performed with severity of COPD using GOLD stage classification between erythrocyte antioxidant enzyme activities with $\mathrm{FEV}_{1}$ is presented in Table 5. In COPD patients, $\mathrm{FEV}_{1}$ showed a significant negative correlation with GST GOLD stage II $(r=-0.735, p<0.001)$ and a positive correlation with GOLD stages III and IV $(r=0.098$ and $r=0.102$, respectively). $\mathrm{FEV}_{1}$ correlated negatively with GR activity in GOLD stages II and III $(r=-0.474, p<0.05$ and $r=-0.315, p<0.05$; respectively) and border line negative significant with GOLD stage III $(r=-0.242, p<0.07)$, TAS also showed a significant negative correlation with $\mathrm{FEV}_{1}(r=-0.383, p<0.05)$ in GOLD stage III, Table 5. To clarify whether the antioxidant enzyme activity and the severity COPD were independently related, a multivariate logistic regression analysis was performed (Table 6). Antioxidant enzyme activities were log transformed prior to analysis. Study variables with a Pearson correlation of

Table 4 Coefficients of correlation values between erythrocyte anti-oxidation enzyme activities with FEV ${ }_{1}$ (\% predicted) in COPD patients

\begin{tabular}{ll}
\hline Study parameters & $\begin{array}{l}\text { Correlation } \\
\text { coefficients }(r)^{*}\end{array}$ \\
\hline Superoxide dismutase (U/mg protein) & $-0.182^{*}$ \\
Catalase (U/mg protein) & $-0.263^{*}$ \\
Glutathione s transferase (U/mg protein) & $0.630^{* *}$ \\
Glutathione peroxidase (U/mg protein) & 0.030 \\
Glutathione reductase (U/mg protein) & -0.094 \\
Total antioxidant status ( $\mu \mathrm{M}$ Fe $\left.{ }^{2+} / 1\right)$ & $-0.183^{*}$ \\
\hline
\end{tabular}

Significance of correlation between erythrocyte antioxidant enzyme activities with $\mathrm{FEV}_{1}$ (\% predicted). ${ }^{*} p<0.05,{ }^{* *} p<0.001,{ }^{\prime} r$ ' denotes Pearson correlation coefficient
Table 5 Coefficients of correlation values between erythrocyte anti-oxidation enzyme activities with $\mathrm{FEV}_{1}$ (\% predicted) in COPD patients according to GOLD stage classification

\begin{tabular}{|c|c|c|c|}
\hline \multicolumn{4}{|c|}{ GOLD stage classification of COPD } \\
\hline Study parameters & $\begin{array}{l}\text { GOLD } \\
\text { stage \| } \\
\text { coefficient }(r)\end{array}$ & $\begin{array}{l}\text { GOLD } \\
\text { stage III } \\
\text { coefficient }(r)\end{array}$ & $\begin{array}{l}\text { GOLD } \\
\text { stage IV } \\
\text { coefficient }(r)\end{array}$ \\
\hline $\begin{array}{l}\text { Superoxide dismutase } \\
\text { (U/mg protein) }\end{array}$ & 0.20 & 0.00 & -0.21 \\
\hline Catalase (U/mg protein) & -0.09 & -0.21 & 0.00 \\
\hline $\begin{array}{l}\text { Glutathione } s \text { transferase } \\
\text { (U/mg protein) }\end{array}$ & $-0.73^{* *}$ & 0.09 & 0.10 \\
\hline $\begin{array}{l}\text { Glutathione peroxidase } \\
\text { (U/mg protein) }\end{array}$ & 0.24 & 0.02 & -0.11 \\
\hline $\begin{array}{l}\text { Glutathione reductase } \\
\text { (U/mg protein) }\end{array}$ & $-0.47^{*}$ & $-0.31^{*}$ & $-0.24^{*}$ \\
\hline $\begin{array}{l}\text { Total antioxidant status } \\
\left(\mu \mathrm{M} \mathrm{Fe}^{2+} / \mathrm{l}\right)\end{array}$ & -0.07 & $-0.38^{*}$ & 0.20 \\
\hline
\end{tabular}

Significance of correlation between erythrocyte antioxidant enzymes activities with $\mathrm{FEV}_{1}$ (\% predicted) according to GOLD stages: $:$

$p<0.07$, Border line significance, ${ }^{*} p<0.05$; ${ }^{*} p<0.001$, ' $r$ ' denotes Pearson correlation coefficient

Table 6 Multivariate logistic regression analysis adusted odds ratio $(95 \% \mathrm{CL})$ for erythrocyte anti-oxidation enzyme activities with severity of COPD according to GOLD stage classification, GOLD stage II, III and IV

\begin{tabular}{lllll}
\hline Variables & GOLD & OR & $95 \% \mathrm{Cl}$ & $p$-values \\
& stages & & & \\
\hline Superoxide dismutase & II & 0.97 & $-0.05-0.01$ & 0.173 \\
(U/mg protein) & II & 0.99 & $-0.02-0.01$ & 0.686 \\
& IV & 1.00 & $-0.00-0.02$ & 0.292 \\
Catalase (U/mg protein) & II & 0.99 & $-0.02-0.00$ & 0.321 \\
& III & 0.99 & $-0.01-0.00$ & 0.551 \\
& IV & 1.00 & $-0.00-0.01$ & 0.849 \\
Glutathione s transferase & II & 1.11 & $0.04-0.18$ & $<0.001$ \\
(U/mg protein) & II & 1.01 & $-0.01-0.05$ & 0.284 \\
& IV & 0.93 & $-0.10-0.01$ & $<0.006$ \\
Glutathione peroxidase & II & 1.02 & $-0.00-0.05$ & 0.082 \\
(U/mg protein) & II & 1.00 & $-0.01-0.01$ & 0.825 \\
& IV & 0.98 & $-0.03-0.00$ & $<0.034$ \\
Glutathione reductase & II & 0.98 & $-0.04-0.00$ & 0.088 \\
(U/mg protein) & III & 0.99 & $-0.01-0.00$ & 0.507 \\
& IV & 1.00 & $-0.00-0.01$ & 0.313 \\
Total antioxidant status & II & 0.99 & $-0.08-0.07$ & 0.886 \\
( $\mu$ M Fe $\left.{ }^{2+} / 1\right)$ & II & 0.97 & $-0.07-0.02$ & 0.274 \\
& IV & 0.95 & $-0.08-0.00$ & $<0.049$ \\
\hline Signifance of differen & & &
\end{tabular}

Significance of difference between erythrocyte antioxidant enzymes activities with $\mathrm{FEV}_{1}$ (\% predicted) $p<0.05$; OR odds ratio, $\mathrm{Cl}$ confidence interval 
coefficient less than 0.11 that did not show multicollinearity with COPD severity: GOLD stage II, III and IV. A multivariate logistic regression analysis confirmed significant independent association between GST (OR $=0.93$; $95 \% \mathrm{CI}=-0.10-0.01 ; p<0.00), \mathrm{GPx}(\mathrm{OR}=0.98 ; 95 \% \mathrm{CI}$ $=-0.03-0.00 ; p<0.05)$ and TAS $(\mathrm{OR}=0.95 ; 95 \% \mathrm{CI}$ $=-0.08-0.00 ; p<0.05)$ and $\mathrm{FEV}_{1}$ in GOLD stage IV. A significant association was observed with GST $(\mathrm{OR}=1.11$; $95 \% \mathrm{CI}=0.04-0.18 ; p<0.001)$, whereas, a border line significant of GPx $(\mathrm{OR}=1.02 ; 95 \% \mathrm{CI}=-0.00-0.05 ; p<$ $0.08)$ and $\mathrm{GR}(\mathrm{OR}=0.98 ; 95 \% \mathrm{CI}=-0.04-0.00 ; p<0.08)$ activities was observed in GOLD stage II, Table 6.

The decrease in the mean value of SOD, CAT in patients of COPD with type 2 diabetes, pulmonary hypertension and cardiovascular disease compared to healthy controls are shown in (Fig. 3a and b). However, this decrease was not statistically significant $(p>0.05)$. Similar result was also noticed in GST and GR activities in COPD patients with type 2 diabetes, pulmonary hypertension and cardiovascular disease when compared to healthy controls (Fig. 3c and d). A significant decrease in the GPx activity $(p<0.001$; Fig. $3 \mathrm{~d})$ and TAS $(p<0.05$; Fig. 3f) in COPD patients with type 2 diabetes were observed compared to healthy controls. No significant differences of GPx and TAS were observed in COPD patients with pulmonary hypertension and cardiovascular disease. However, in COPD comorbidities multivariate logistic regression analysis confirmed a border line significant difference in GPx activity in COPD with T2D $(\mathrm{OR}=0.04 ; 95 \% \mathrm{CI}=-6.60-0.53 ; p=0.09)$, and GST activity in COPD - CVD $(\mathrm{OR}=2.51 ; 95 \% \mathrm{CI}=0.00-1.84$; $p<0.05)$ patients when compared to non-comorbid patients, Table 7.

\section{Discussion}

It is now evident that COPD is a leading cause of hospitalizations in adults, particularly older people. In fact, recent medical research indicates that antioxidants eventually could represent a promising therapy for COPD. Further, comorbidities have been a common cause, contributing to many of these ICU hospitalizations. This investigation has determined important risk factors in COPD namely the role of erythrocyte antioxidants related to disease severity. An important feature in the pathogenesis of COPD is oxidative stress. The relationship between COPD and oxidative stress parameters has been extensively studied in different populations across the world [33, 34], but very few studies are available in the Indian population, especially in south India [35]. This study showed that COPD patients had decreased SOD activity as compared to controls, which has been one of the most consistent findings across several studies in many countries [36]. In the present study, CAT activity was found to be reduced in COPD patients. Consistent with our result, a study in erythrocyte red blood cells showed decreased CAT activity in patients with COPD $[35,36]$. In contrast, a study on single nucleotide polymorphism in CAT gene $(-262 \mathrm{C}>\mathrm{T})$ showed that erythrocyte catalase activity was higher in COPD patients with the $\mathrm{C} / \mathrm{C}$ genotype, and with the combined $\mathrm{C} / \mathrm{T}$ and $\mathrm{T} / \mathrm{T}$ genotypes, than in healthy controls [37]. Our study supports the finding of Tavilani et al., which reported an increase in SOD and CAT activities in alveolar macrophages of elderly smokers [38]. Kirkil et al. reported that the plasma levels of SOD and CAT decreased in the COPD group [39]. However, we found a dramatic increase in SOD and CAT activities among patients with more severe COPD. It was found that erythrocyte SOD and CAT activities gradually increased from GOLD stages I to IV in COPD patients, which is supported by previous reports [36-41]. Indeed, various studies [40-42] except one study [7] have suggested that certain markers of oxidative stress may be related to tobacco smoking or to the severity of COPD.

In the present study, we found that erythrocyte GST activity significantly decreased in COPD patients. A possible explanation for this decrease in activity of GST could be that in COPD patients the increase in toxic substrates in the body, reduces the GST activity which was inversely proportional to the increased $\mathrm{FEV}_{1}$. Also it is known that GST is influenced by nuclear factor, erythroid-derived 2, like 2 (Nrf2), a transcription factor that contributes to the induction of several protective enzymes during oxidative stress [43]. Another possible explanation could be due to the high levels of GSH in the epithelial lining of the lungs, which regulate GSH homeostasis by the GST enzymes that participate in the transport and detoxification mechanism.

Hence it is suggested that there may be a strong association of GST with lung function at the molecular level [44-48]. Interestingly, in this investigation, we also found GST activity was not only lower in COPD but also progressively decreased with the severity of COPD disease. Our study observed not only lowered level of GPx activity in COPD patients, but also a uniform decrease in GPx activities from GOLD stage II to IV. These findings suggest that the lower activity of GPx in erythrocytes may be associated with the severity of COPD. However, there is recent evidence suggesting that transgenic GPx-1 mice protect lungs from cigarette smokeinduced lung inflammation [49]. Our present study found a significant positive correlation between GPx and $\mathrm{FEV}_{1}$ in COPD patients.

It was observed that erythrocyte GR activity was lower in COPD patients, similar findings were also reported by a few authors $[38,50]$ whereas, Gosker et al. reported an increase glutathione activity in skeletal muscle of patients with COPD [51]. This investigation supports the fact that in COPD patients oxidative stress deactivates 

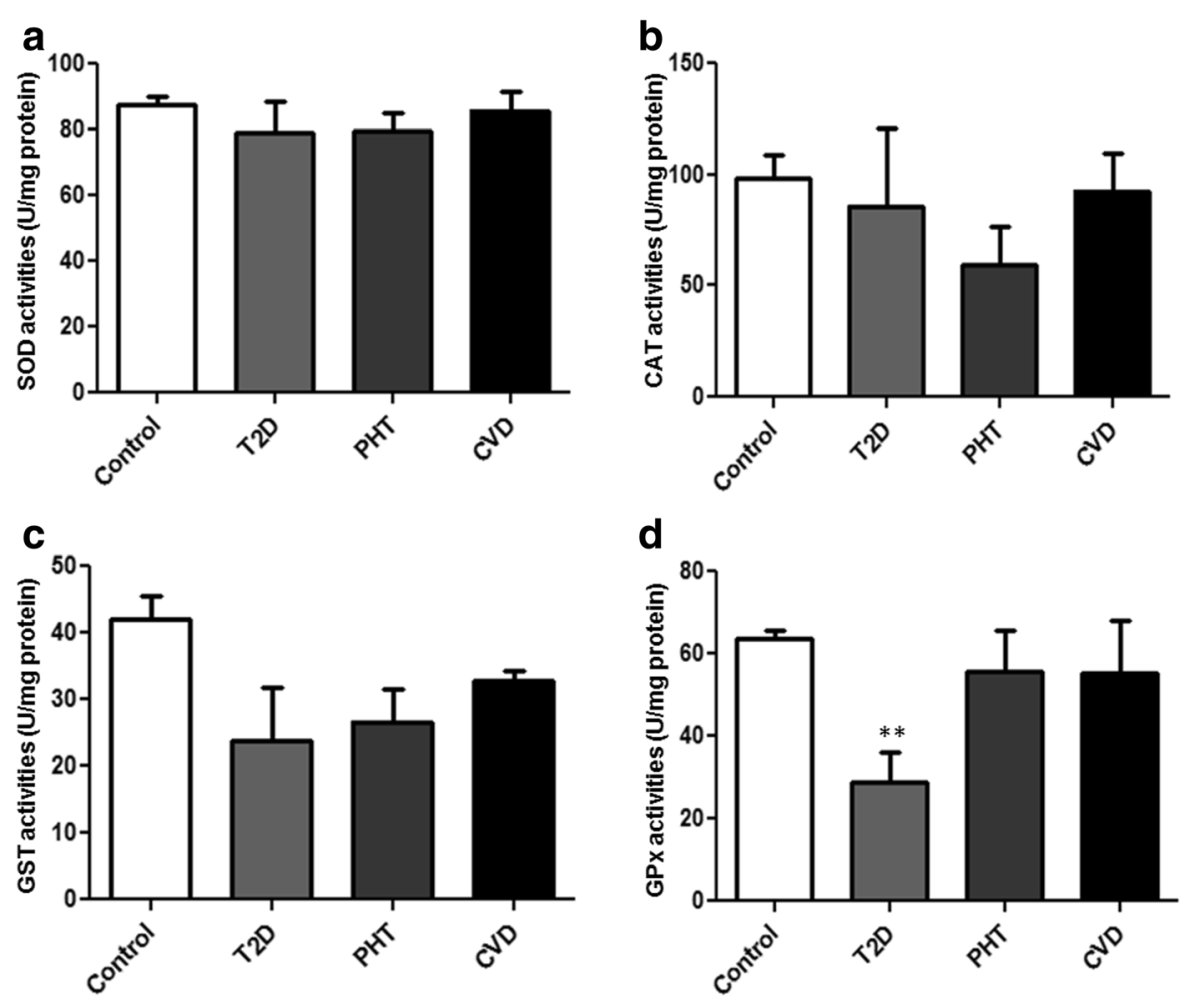

d
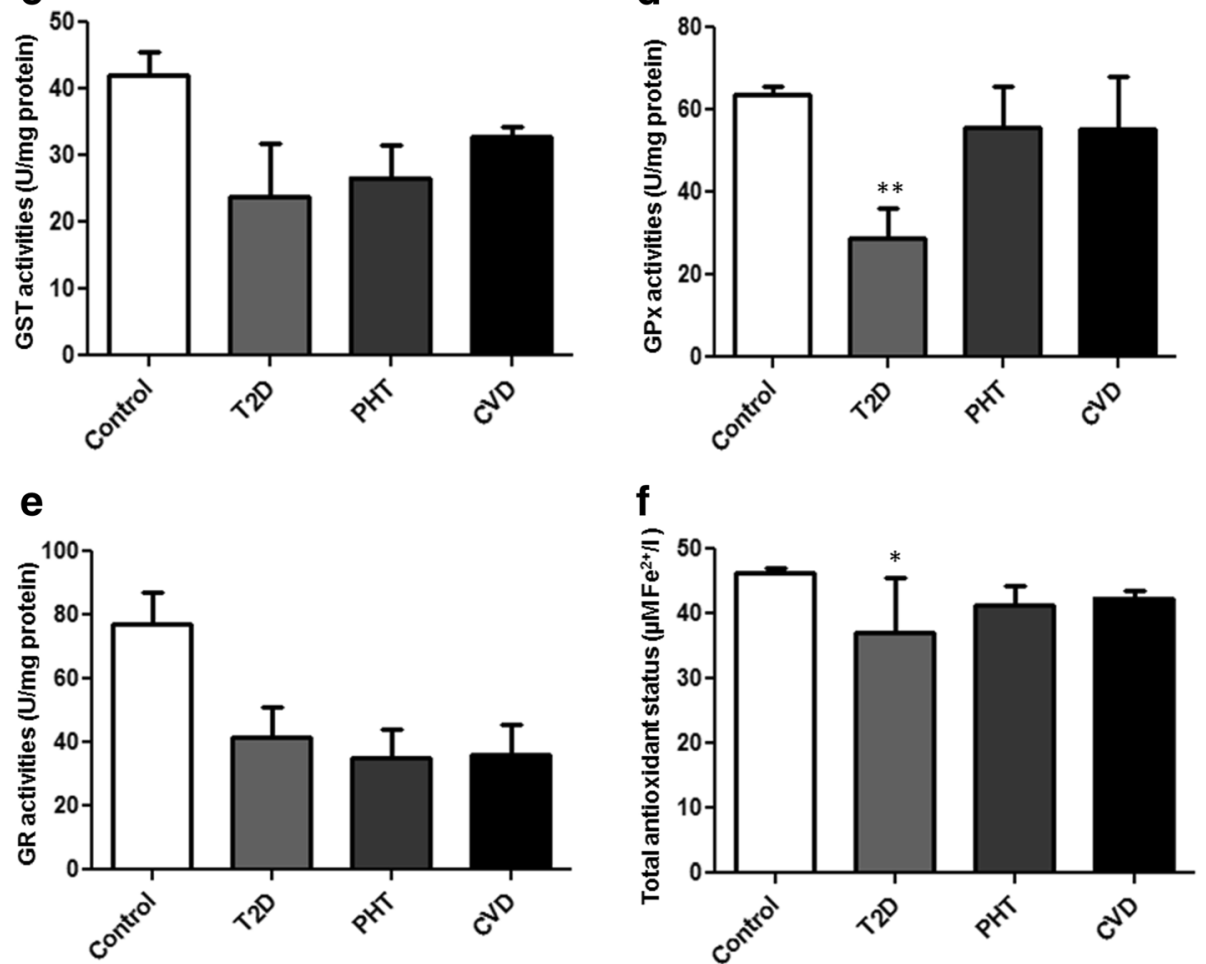

Fig. 3 Antioxidant enzyme activities in COPD patients with T2D, PHT and CVD and compared with the healthy controls. Erythrocytes (a) SOD, superoxide dismutase; b CAT, catalase; c GST, glutathione-s-transferase; $\mathbf{d}$ GPx, glutathione peroxidase; e GR, glutathione reductase; expressed as U/mg protein and (f) TAS, total antioxidant status; expressed as $\mu \mathrm{M} \mathrm{Fe}{ }^{2+} /$. Data expressed as Mean \pm SEM: standard error of the mean; Significance of difference between COPD and type 2 diabetes (T2D), pulmonary hypertension (PHT) and cardiovascular disease (CVD) to control: Significant differences and respective $p$ values ${ }^{*} p<0.05,{ }^{* *} p<0.001$ are mentioned on the graph using one-way ANOVA followed by Bonferroni's multiple comparison post hoc test

the regulatory enzymes such as GPx, GST and GR involved in the GSH/GSSG redox system which may be involved in the protection of cellular and mitochondrial functions in the lungs. Activity of GR increased from GOLD stage II to IV, TAS in erythrocytes was lower in COPD patients. A decrease in TAS suggests that there was an increase in oxidative stress in COPD patients; Rahman et al [52] also reported similar findings. With the increase in severity of COPD from GOLD stage II to IV we observed a significant decrease in the level of TAS. Correlation analysis revealed a significant negative correlation between erythrocyte SOD, CAT, GR and TAS with $\mathrm{FEV}_{1}$ in COPD patients. Previously a significant positive correlation between SOD and CAT with $\mathrm{FEV}_{1}$ was described in erythrocytes of COPD patients $[35,36]$. One reason for failing to find a significant positive correlation between erythrocyte SOD or CAT and $\mathrm{FEV}_{1}$ may be due to the phenomenon that various enzymatic systems differ substantially in their responses to smoking-induced increases in oxidative stress [53].

In this study, of all the enzymes assayed, only GST and GPx showed a significant positive correlation with $\mathrm{FEV}_{1}$ 
Table 7 Multivariate logistic regression analysis adusted odds ratio $(95 \% \mathrm{CL})$ for antioxidant enzyme activities with COPD comorbidities: type 2 diabetes, pulmonary hypertension and cardiovascular

\begin{tabular}{|c|c|c|c|c|}
\hline Variables & $\begin{array}{l}\text { COPD } \\
\text { co-morbidities }\end{array}$ & OR & $95 \% \mathrm{Cl}$ & $p$-values \\
\hline \multirow{3}{*}{$\begin{array}{l}\text { Superoxide dismutase } \\
\text { (U/mg protein) }\end{array}$} & $\mathrm{T} 2 \mathrm{D}$ & 1.99 & $-1.11-2.49$ & 0.453 \\
\hline & PHT & 1.61 & $-0.57-1.53$ & 0.374 \\
\hline & CVD & 2.32 & $-0.35-2.04$ & 0.169 \\
\hline \multirow[t]{3}{*}{ Catalase (U/mg protein) } & $\mathrm{T} 2 \mathrm{D}$ & 1.98 & $-0.62-2.00$ & 0.306 \\
\hline & PHT & 0.80 & $-1.14-0.70$ & 0.642 \\
\hline & CVD & 1.77 & $-0.30-1.45$ & 0.199 \\
\hline \multirow{3}{*}{$\begin{array}{l}\text { Glutathione s transferase } \\
\text { (U/mg protein) }\end{array}$} & $\mathrm{T} 2 \mathrm{D}$ & 0.90 & $-1.39-1.18$ & 0.873 \\
\hline & PHT & 1.41 & $-0.57-1.26$ & 0.462 \\
\hline & CVD & 2.51 & $0.00-1.84$ & $<0.049$ \\
\hline \multirow{3}{*}{$\begin{array}{l}\text { Glutathione peroxidase } \\
\text { (U/mg protein) }\end{array}$} & $\mathrm{T} 2 \mathrm{D}$ & 0.04 & $-6.60-0.53$ & $<0.096$ \\
\hline & PHT & 0.82 & $-1.12-0.72$ & 0.677 \\
\hline & CVD & 0.63 & $-1.52-0.59$ & 0.392 \\
\hline \multirow{3}{*}{$\begin{array}{l}\text { Glutathione reductase } \\
\text { (U/mg protein) }\end{array}$} & $\mathrm{T} 2 \mathrm{D}$ & 0.58 & $-1.76-0.70$ & 0.400 \\
\hline & PHT & 0.52 & $-1.67-0.40$ & 0.228 \\
\hline & CVD & 0.57 & $-1.60-0.49$ & 0.299 \\
\hline \multirow{3}{*}{$\begin{array}{l}\text { Total antioxidant status } \\
\left(\mu \mathrm{M} \mathrm{Fe}{ }^{2+} / \mathrm{I}\right)\end{array}$} & $\mathrm{T} 2 \mathrm{D}$ & 1.04 & $-1.07-1.16$ & 0.934 \\
\hline & PHT & 1.26 & $-0.61-1.08$ & 0.589 \\
\hline & CVD & 1.69 & $-0.45-1.50$ & 0.291 \\
\hline
\end{tabular}

Significance of difference between erythrocyte antioxidant enzyme activities with COPD comorbidities: type 2 diabetes (T2D), pulmonary hypertension (PHT) and cardiovascular disease (CVD) $p<0.05$; Border line significance: if $p<0.09$; OR odds ratio, $\mathrm{Cl}$ confidence interval

in COPD patients. Previous reports have also found a significant positive correlation between erythrocytes GST activity [35] and GPx [36] with lung function, reflected by $\mathrm{FEV}_{1}$. In agreement with the positive correlation of GST and GPx in erythrocyte of COPD patients, a recent study has shown a significant direct relationship between $\mathrm{FEV}_{1}$ and erythrocyte GPx activity [48]. To our knowledge, there are no previous studies which have evaluated the erythrocytes antioxidant enzyme activities correlating with disease severity using pulmonary function test assessed as $\mathrm{FEV}_{1}$ in COPD. We found that SOD and GPx activities were positively correlated with $\mathrm{FEV}_{1}$. Conversely, CAT, GST, GR and TAS showed significant negative correlation with $\mathrm{FEV}_{1}$. The risk conferred by GST and GPx towards progression of the COPD severity was further evaluated using multinomial logistic regression analysis by taking GOLD stages as reference category. Increase in GST and GPx activities was found to confer greater risk of progression to GOLD stage II and IV. Kluchová et al [48] reported a similar trend. In their study, the authors measured and compared GPx activity in patients with moderate and severe COPD. They found that a significant direct relationship between $\mathrm{FEV}_{1}$ and erythrocyte GPx activity with severity of COPD. Our findings extend those of Duthie et al. who reported that erythrocyte GPx activity is associated not only with smoking status but also with severity of COPD [54]. The significant correlation found between the enzymes and $\mathrm{FEV}_{1}$ suggests that decrease in antioxidant enzyme activities might be the result of greater airway obstruction in COPD patients.

An interesting finding in the current analysis was the antioxidant enzyme activities in COPD comorbidities. We found no significant variations in erythrocyte SOD, CAT, GST and GR activity in COPD patients with type 2 diabetes, pulmonary hypertension and cardiovascular disease compared to control group. Whereas, erythrocyte GPx activity and TAS showed a significant decrease in the mean value of COPD patients with type 2 diabetes. Joppa et al. also reported a significant decrease in the GPx activity in erythrocyte of COPD patients with and without pulmonary hypertension [55]. Some of the previous finding of Orhan et al. showed a significant increase in plasma GPx activity in hypertensive preeclamptic pregnancy and also in insulin dependent diabetic pregnancy [56]. Further, it was observed that the standard dietary treatment for type 2 diabetic patients produced an increase of the SOD and GPx activities [57].

However, this may suggest that the COPD comorbidities are an independent risk factor for the development of COPD. This finding was substantiated by multivariate logistic regression analysis, which demonstrated that the GPx activity was significantly independently association of COPD - type 2 diabetes. Whereas, our present study showed that there was no statistically significant independent association of antioxidant enzyme activity in COPD - pulmonary hypertension. Similar finding was report by Al Shebly et al [58]; this study found no statistically significant difference in plasma GSH-Red activity during labor in diabetic, hypertensive, and control women. More recently, it was clarified that a significant increase of GPx and GSH activities in hypertensive disorders of pregnant women.

Logistic regression analysis of comorbidities, in our study, showed significant difference in GST activity between COPD - cardiovascular disease patients and GPx activity in COPD - type 2 diabetes patients and patients without comorbidities, suggesting that these enzymes could serve as a critical marker to assess oxidative damage in COPD patients with cardiovascular disease and type 2 diabetes. Conversely, there was no significant difference in the activities of the other antioxidant enzymes in patients with and without comorbidities, which could indicate that these comorbidities may not confer significant additive oxidative stress in the COPD patients. Therefore, we propose that elevated level of GPx activity in COPD patients with type 2 diabetes may be a useful 
biomarker linked to an increase in oxidative stress. Surprisingly, our present study showed no significant enzyme activities in COPD patients with pulmonary hypertension. However, there are a number of conflicting reports as well $[59,60]$. Hence, our study may have useful clinical implications in view of increased understanding of COPD risk parameters with comorbid diseases.

\section{Conclusions}

The present study provides a strong evidence for the oxidant-antioxidant imbalance in the pathogenesis of COPD. Our study is the first, to our knowledge, to examine the correlation between $\mathrm{FEV}_{1}$ and antioxidant enzyme activities among the different stages of COPD and highlights a strong correlation between $\mathrm{FEV}_{1}$, GST and GPx enzyme activity with severity of the COPD disease. This study also demonstrated for the first time that there exits an oxidative stress in COPD patients with comorbidities such as type 2 diabetes, pulmonary hypertension and cardiovascular disease. Further, it is likely that antioxidants may have in future combination therapies for COPD patients. This study may have useful clinical implications in view of increased understanding of COPD risk parameters. It has also been recognized that additional burden of comorbidities has negative impact on economies and also patient related outcomes.

\section{Abbreviations \\ CAT: Catalase; COPD: Chronic obstructive pulmonary disease; CVD: Cardiovascular disease; $\mathrm{FEV}_{1}$ : Forced expiratory volume in $1 \mathrm{~s}$; FEV 1 /FVC: Forced expiratory volume in $1 \mathrm{~s} /$ forced vital capacity ratio; FVC: Force vital capacity; GOLD: Global initiative for chronic obstructive lung disease; GPx: Glutathione peroxidase; GR: Glutathione reductase activities; GST: Glutathione-s-transferase; $\mathrm{NCMH}$ : National commission on macroeconomics and health; PaO2: Partial pressure of oxygen; PHT: Pulmonary hypertension; SaO2: Arterial oxygen saturation; SOD: Superoxide dismutase; T2D: Type 2 diabetes; TAS: Total antioxidant status}

\section{Acknowledgments}

We thank JNIAS, Hyderabad for the laboratory facilities provided for this work. Special thanks to Dr. Archana and Mr. Sai Kumar for their support throughout this project. Most importantly we thank our study group for their cooperation and patience in filling in the demographic details.

\section{Funding}

there has been no financial support for this project.

\section{Availability of data and materials}

The data that support the findings of this study are available from the corresponding author.

\section{Authors' contributions}

MA and $\mathrm{KJ}$ designed the research project. MA, GV, MSA, SVR and KJ analyzed the data. All authors contributed in writing, revising and approving the manuscript for submission. All authors read and approved the final manuscript.

\section{Authors' information}

GV, SVR and KJ are professor. MSA is senior pulmonologist and MA is Assistant Director.

\section{Competing interests}

The authors declare that they have no conflict of interest.

\section{Consent for publication}

The patients and controls were informed about the study and purpose; and gave written informed consent before inclusion in the study group.

Ethics approval and consent to participate

The study was conducted in accordance with the guidelines of Committee responsible for human studies as guided by the "Declaration of Helsinki" and good clinical practice. The study was approved by the Ethics Committee of Mahavir Hospital and Research Centre - Hyderabad.

\section{Publisher's Note}

Springer Nature remains neutral with regard to jurisdictional claims in published maps and institutional affiliations.

\section{Author details}

${ }^{1}$ Department of Biotechnology, GITAM Institute of Science, GITAM University, Visakhapatnam, Andhra Pradesh 530045, India. ${ }^{2}$ Center for Biotechnology and Bioinformatics (CBB), Jawaharlal Nehru Institute of Advance Studies (JNIAS), Hyderabad 500003, Telangana, India. ${ }^{3}$ Department of Biotechnology, GITAM Institute of Technology, GITAM University, Visakhapatnam, Andhra Pradesh 530045, India. ${ }^{4}$ Bhagwan Mahavir Medical Research Centre, Hyderabad 500004, Telangana, India.

Received: 28 December 2016 Accepted: 23 March 2017

Published online: 30 March 2017

\section{References}

1. Pauwels RA, Buist AS, Calverley PM, Jenkins CR, Hurd SS. Global strategy for the diagnosis, management, and prevention of chronic obstructive pulmonary disease. NHLBI/WHO global initiative for chronic obstructive lung disease (GOLD) workshop summary. Am J Respir Crit Care Med. 2001; 163(5):1256-76.

2. Lopez AD, Shibuya K, Rao C, Mathers CD, Hansell AL, Held LS, et al. Chronic obstructive pulmonary disease: current burden and future projections. Eur Respir J. 2006:27(2):397-412.

3. Hogg JC, Chu F, Utokaparch S. The nature of small-airway obstruction in chronic obstructive pulmonary disease. N Engl J Med. 2004;350(26):2645-53.

4. US Department of Health and Human Services. Chronic obstructive pulmonary disease. Washington: USDHHS; 2003. Data fact sheet.

5. Murthy KJR, Sastry JG. Economic burden of chronic obstructive pulmonary disease. National Commission on Macroeconomics and Health (NCMH) background papers. 2005. p. 265-74. [cited 2014 Nov 17]. Available from: https://www.scribd.com/document/88538243/Commision-on-Macroeconomicand-Health-Bg-P2-Burden-of-Disease-Estimations-and-Casual-Analysis.

6. Rahman I, MacNee W. Oxidant/antioxidant imbalance in smokers and chronic obstructive pulmonary disease. Thorax. 1996;51:348-50.

7. Rahman I, MacNee W. Lung glutathione and oxidative stress:implications in cigarette smoke induced airway disease. Am J Physiol. 1999;277:1067-88.

8. MacNee W, Rahman I. Is oxidative stress central to the pathogenesis of chronic obstructive pulmonary disease. Trends Mol Med. 2000;7:55-62.

9. MacNee W. Oxidants/antioxidants and COPD. Chest. 2000;117:303S-175.

10. Ahmad A, Shameem M, Husain Q. Relation of oxidantantioxidant imbalance with disease progression in patients with asthma. Ann Thorac Med. 2012;7:226-32.

11. Pryor WA, Stone K. Oxidants in cigarette smoke: radicals, hydrogen peroxide, peroxynitrate, and peroxynitrite. Ann NY Acad Sci. 1993;686:12-28.

12. Eiserich JP, Cross CE, Van der Vliet A. Nitrogen oxides are important contributors to cigarette smoke induced ascorbate oxidation. In: Packer L, Fuchs J, editors. Vitamin C in health and disease. New York: Dekker; 1997. p. 399-412.

13. Kinnula VL. Focus on antioxidant enzymes and antioxidant strategies in smoking related airway diseases. Thorax. 2005;60:693-700.

14. Vlahos R, Bozinovski S. Glutathione peroxidase-1 as a novel therapeutic target for COPD. Redox Rep. 2013;18(4):142-9.

15. Brigelius-Flohe R. Glutathione peroxidases and redox-regulated transcription factors. Biol Chem. 2006;387:1329-35.

16. Bernardo I, Bozinovski S, Vlahos R. Targeting oxidant-dependent mechanisms for the treatment of COPD and its comorbidities. Pharmacol Ther. 2015; 155:60-79.

17. Pannala VR, Bazil JN, Camara AK, Dash RK. A biophysically based mathematical model for the catalytic mechanism of glutathione reductase. Free Radic Biol Med. 2013;65:1385-97. 
18. Duthie GG, Arthur JR, James WP. Effects of smoking and vitamin E on blood antioxidant status. Am J Clin Nutr. 1991;53:1061-3.

19. Rahman I. Antioxidant therapies in COPD. Int J Chron Obstruct Pulmon Dis. 2006;1:15-29.

20. MacNee W. Pathogenesis of chronic obstructive pulmonary disease. Proc Am Thorac Soc. 2005;2:258-66.

21. Rahman I, Swarska E, Henry M, Stolk J, MacNee W. Is there any relationship between plasma antioxidant capacity and lung function in smokers and in patients with chronic obstructive pulmonary disease. Thorax. 2000;55(3):189-93.

22. Mannino DM, Thorn D, Swensen A, Holguin F. Prevalence and outcomes of diabetes, hypertension and cardiovascular disease in COPD. Eur Respir J. 2008;32(4):962-9.

23. Sin DD, Man SF. Chronic obstructive pulmonary disease as a risk factor for cardiovascular morbidity and mortality. Proc Am Thorac Soc. 2005;2:8-11.

24. Leone N, Courbon D, Thomas F, Bean K, Jégo B, Leynaert B, et al. Lung function impairment and metabolic syndrome: the critical role of abdominal obesity. Am J Respir Crit Care Med. 2009;179:509-16.

25. Wells CE, Baker EH. Type 2 diabetes mellitus \& chronic obstructive pulmonary disease: need for a double-pronged approach. Diabetes Manag. 2014;4(4):307-10

26. Global Initiative for Chronic Obstructive Lung Disease, 2006. Global strategy for the diagnosis, management, and prevention of COPD. Executive summary. National Institutes of Health. [cited 2014 Nov 22]. Available from URL: http:// www.goldcopd.org/uploads/users/files/GOLDReport2006 =0122.pdf.

27. Marklund S, Marklund G. Involvement of the superoxide anion radical in the autoxidation of pyrogallol and a convenient assay for superoxide dismutase. Eur J Biochem. 1974;47:469-74.

28. Aebi H. Catalase in vitro. Methods Enzymol. 1984;105:121-6.

29. Beutler E. A manual of biochemical methods. 3rd ed. London: GruneadStration Inc; 1984. p. 8-78. Red cell metabolism.

30. Flohe L, Gunzler WA. Assays of glutathione peroxidase. Methods Enzymol. 1984;105:114-21.

31. Carlberg I, Mannervik B. Purification and characterization glutathione reductase from calf liver. An improved procedure for affinity chromatography on 2', 5'ADP Sepharose 4B. Anal Biochem. 1981;116:531-6.

32. Benzie IFF, Strain JJ. Ferric reducing antioxidant power assay: direct measure of total antioxidant activity of biological fluids and modified version for simultaneous measurement of total antioxidant power and ascorbic acid concentration. Methods Enzymol. 1999;299:15-27.

33. Chan-Yeung M, Ait-Khaled N, White N, Ip MS, Tan WC. The burden and impact of COPD in Asia and Africa. Int J Tuberc Lung Dis. 2004;8(1):1-14.

34. Drost EM, Skwarski KM, Sauleda J, Soler N, Roca J, Agusti A, et al. Oxidative stress and airway inflammation in severe exacerbations of COPD. Thorax. 2005;60(4):293-300.

35. Arja C, Surapaneni KM, Raya P, Adimoolam C, Balisetty B, Kanala KR, et al. Oxidative stress and antioxidant enzyme activity in South Indian male smokers with chronic obstructive pulmonary disease. Respirology. 2013; 18(7):1069-75.

36. Ahmad M, Shameem Q, Husain. Altered oxidant-antioxidant levels in the disease prognosis of chronic obstructive pulmonary disease. Int J Tuberc Lung Dis. 2013;17(8):1104-9.

37. Mak JC, Ho SP, Yu WC, Choo KL, Chu CM, Yew WW, et al. Polymorphisms and functional activity in superoxide dismutase and catalase genes in smokers with COPD. Eur Respir J. 2007;30:684-90.

38. Tavilani H, Nadi E, Karimi J, Goodarzi MT. Oxidative stress in COPD patients, smokers, and non-smokers. Respir Care. 2012;57(12):2090-4.

39. Kırkıla G, Muza MH, Seckin D, Sahin K, Kucuk O. Antioxidant effect of zinc picolinate in patients with chronic obstructive pulmonary disease. Respir Med. 2008;102(6):840-4.

40. Rai RR, Phadke MS. Plasma oxidant-antioxidant status in different respiratory disorders. Ind J Clin Biochem. 2006;21(2):161-4.

41. Harju T, Kaarteenaho-Wiik R, Sirvio R. Manganese superoxide dismutase is increased in the airways of smokers' lungs. Eur Respir J. 2004;24(5):765-71.

42. Petruzzelli S, Hietanen E, Bartsch $H$, Camus AM, Mussi A, Angeletti CA, et al. Pulmonary lipid peroxidation in cigarette smokers and lung cancer patients. Chest. 1990;98(4):930-5.

43. Walters DM, Cho HY, Kleeberger SR. Oxidative stress and antioxidantsin the pathogenesis of pulmonary fibrosis: apotential role for Nrf2. Antioxid Redox Signal. 2008;10(2):321-32.

44. Orhan H, Evelo CTA, Sahin G. Erythrocyte antioxidant defense response against cigarette smoking in humans - the glutathione S-transferase vulnerability. J Biochem Mol Toxicol. 2005;19:226-33.
45. Mehrotra S, Sharma A, Kumar S. Polymorphism of glutathione S-transferase M1 and T1 gene loci in COPD. Int J Immunogenet. 2010;37(4):263-7.

46. Imboden M, Downs SH, Senn O. Glutathione S-transferase genotypes modify lung function decline in the general population: SAPALDIA cohort study. Respir Res. 2007:8:2.

47. Lakhdar R, Denden S, Mouhamed MH. Correlation of EPHX1, GSTP1, GSTM1, and GSTT1 genetic polymorphisms with antioxidative stress markers in chronic obstructive pulmonary disease. Exp Lung Res. 2011;37(4):195-204.

48. Kluchova Z, Petrasova D, Joppa P, Dorkova Z, Tkacova R. The association between oxidative stress and obstructive lung impairment in patients with COPD. Physiol Res. 2007;56(1):51-6.

49. Duong C, Seow HJ, Bozinovski S, Crack PJ, Anderson GP, Vlahos, et al. Glutathione peroxidase-1 protects against cigarette smoke-induced lung inflammation in mice. Am J Physiol Lung Cell Mol Physiol. 2010;299:L425-33.

50. Ruzena JT, Darina P, Zuzana K, Pavol J, Roman K, Zuzana D, et al. Lipid peroxidation and glutathione peroxidase activity in patients with copd: relationship to disease severity. Chest. 2005;128:131S.

51. Gosker HR, Bast A, Haenen GR, Fischer MA, van der Vusse GJ, Wouters EF, et al. Altered antioxidant status in peripheral skeletal muscle of patients with COPD. Respir Med. 2005;99:118-25.

52. Rahman I. The role of oxidative stress in the pathogenesis of COPD: implications for therapy. Treat Respir Med. 2005;4:175-200.

53. Repine JE, Bast A, Lankhorst I, the oxidative stress study group. Oxidative stress in chronic obstructive pulmonary disease. Am J Respir Crit Care Med. 1997;156:341-57.

54. Duthie GG, Arthur JR. Cigarette smoking as an inducer of oxidative stress. In Exercise and Oxygen Toxicity. 1994;297-317.

55. Joppa P, Petrásová D, Stancák B, Dorková Z, Tkácová R. Oxidative stress in patients with COPD and pulmonary hypertension. Wien Klin Wochenschr. 2007;119(13-14):428-34.

56. Orhan H, Onderoglu LO, Yücel A, Sahin G. Circulating biomarkers of oxidative stress in complicated pregnancies. Arch Gynecol Obstet. 2003; 267(4):189-95.

57. Sekeroğlu MR, Sahin H, Dülger H, Algün E. The effect of dietary treatment on erythrocyte lipid peroxidation, superoxide dismutase, glutathione peroxidase and serum lipid peroxidation in patients with type 2 diabetes mellitus. Clin Biochem. 2000;33:669-74.

58. Al-Shebly MM, Mansour MA. Evaluation of Oxidative Stress and Antioxidant Status in Diabetic and Hypertensive Women during Labor. Oxid Med Cell Longev. 2012;2012:1-6.

59. Hubel CA, Roberts JM, Taylor RN, Musci TJ, Rogers GM, McLaughlin MK, et al. Lipid peroxidation in pregnancy: new perspectives on preeclampsia. Am J Obstet Gynecol. 1989;161(4):1025-34.

60. Wickens D, Wilkins MH, Lunec J. Free-radical oxidation (peroxidation) products in plasma in normal and abnormal pregnancy. Ann Clin Biochem. 1981;18(3):158-62.

\section{Submit your next manuscript to BioMed Central and we will help you at every step:}

- We accept pre-submission inquiries

- Our selector tool helps you to find the most relevant journal

- We provide round the clock customer support

- Convenient online submission

- Thorough peer review

- Inclusion in PubMed and all major indexing services

- Maximum visibility for your research

Submit your manuscript at www.biomedcentral.com/submit 